\title{
PENGARUH PENGALAMAN, KEAHLIAN, SITUASI AUDIT, DAN ETIKA TERHADAP SKEPTISISME PROFESIONAL AUDITOR
} (Studi Kasus pada KAP di Provinsi Daerah Istimewa Yogyakarta)

\author{
Ndaru Winantyadi \\ Alumni Prodi Akuntansi Universitas Negeri Yogyakarta \\ ndaru.uny@gmail.com \\ Indarto Waluyo \\ Jurusan Pendidikan Akuntansi Universitas Negeri Yogyakarta
}

\begin{abstract}
Abstrak: Pengaruh Pengalaman, Keahlian, Situasi Audit, dan Etika terhadap Skeptisisme Profesional Auditor. Penelitian ini bertujuan untuk mengetahui pengaruh Pengalaman, Keahlian, Situasi Audit, dan Etika terhadap Skeptisisme Profesional Auditor baik secara parsial maupun secara simultan. Penelitian ini adalah penelitian sampel dengan jumlah sampel 37 auditor. Uji coba instrument dilakukan menggunakan uji coba terpakai dilakukan pada KAP di Daerah Istimewa Yogyakarta. Uji validitas menggunakan correlation product moment, sedangkan uji reliabilitas menggunakan cronbach alpha. Uji asumsi klasik meliputi uji normalitas, uji linearitas, uji multikolinearitas, dan uji heteroskedastisitas. Uji hipotesis pada penelitian ini menggunakan analisis regresi sederhana dan analisis regresi berganda. Hasil penelitian ini menunjukkan bahwa: (1) Terdapat pengaruh positif dan signifikan Pengalaman terhadap Skeptisisme Profesional Auditor pada KAP di Daerah Istimewa Yogyakarta. Ditunjukkan dengan nilai signifikansi lebih kecil dari level of significant $(0,005<0,050)$, dan garis regresinya $\mathrm{Y}=46,084+1,389 \mathrm{X}_{1}$; (2) Terdapat pengaruh positif dan signifikan Keahlian terhadap Skeptisisme Profesional Auditor. Ditunjukkan dengan nilai signifikansi lebih kecil dari level of significant $(0,000<0,050)$, dan garis regresinya $\mathrm{Y}=40,379+1320 \mathrm{X}_{2}$; (3) Terdapat pengaruh positif dan signifikan Situasi Audit terhadap Skeptisisme Profesional Auditor. Ditunjukkan dengan nilai signifikansi lebih kecil dari pada level of significant $(0,000<0,050)$, dan garis regresinya $\mathrm{Y}=28,818+$ $1,350 X_{3}$; (4) Terdapat pengaruh positif dan signifikan Etika terhadap Skeptisisme Profesional Auditor. Ditunjukkan dengan nilai signifikansi lebih kecil dari level of significant $(0,000<0,050)$, dan garis regresinya $\mathrm{Y}=33,296+0,596 \mathrm{X}_{4} ;(5)$ Terdapat pengaruh positif dan signifikan secara simultan antara Pengalaman, Keahlian, Situasi Audit dan Etika terhadap Skeptisisme Profesional Auditor. Ditunjukan dengan nilai signifikansi lebih kecil dari level of significant $(0,005<0,050)$, dan garis regresinya $\mathrm{Y}=22,230+0,694 \mathrm{X}_{1}+0,613 \mathrm{X}_{2}+0,594 \mathrm{X}_{3}$ $+0,322 \mathrm{X}_{4}$.
\end{abstract}

Kata Kunci: Pengalaman, Keahlian, Situasi Audit, Etika, Skeptisisme Profesional Auditor.

Abstract: The Effect of Experience, Expertise, Audit Situation and Ethics toward Auditor Professional Scepticism. This research to determine the effect of Experience, Expertise, Situation Audit, and Ethics of the Auditor Professional Skepticism either partially or simultaneously. This study is sampling research with a sample of 37 auditors. Trials conducted using test instrument used was the KAP in Yogyakarta Special Region. The validity 
test uses the product moment correlation, while the reliability test uses Cronbach alpha. The classical includes assumption normality test, linearity test, multicollinearity test, and heteroscedasticity test. Hypothesis testing in this research uses simple regression analysis and multiple regression analysis. The results showed that: (1) There is a positive and significant impact of the experience on KAP Auditor Professional Skepticism in Yogyakarta Special Region. Shown with a significance value smaller than the level of significant $(0.005<0.050)$, and the regression line $Y=46.084+1.389 X_{1}$; (2) There is a positive and significant impact Expertise on Auditor Professional Skepticism. Shown with a significance value smaller than the level of significant $(0.000<0.050)$, and the regression line $Y=40.379$ $+1320 X_{2}$; (3) There is a positive and significant impact on audit situation Auditor Professional Skepticism. Indicated by the significance value is less than the level of significant $(0.000<0.050)$, and the regression line $Y=28.818+1.350 X_{3}$; (4) There is a positive and significant impact Auditor Ethics for Professional Skepticism. Shown with a significance value smaller than the level of significant $(0.000<0.050)$, and the regression line $Y=33.296+0.596 X_{4}$; (5) There is a positive and significant impact simultaneously the Experience, Expertise, Situation Audit, and Ethics of the Auditor Professional Skepticism. Indicated by the value of the significance level of less than significant $(0.005<0.050)$, and the regression line $Y=22.230+0.694 X_{1}+0.613 X_{2}+0.594 X_{3}+0.322 X_{4}$.

Keywords: Experience, Expertise, Situation Audit, Ethics, Auditor Professional Skepticism.

\section{PENDAHULUAN}

Pemeriksaan laporan keuangan yang dilakukan auditor dimaksudkan agar pengguna laporan keuangan mempunyai keyakinan bahwa laporan keuangan yang disajikan oleh manajemen perusahaan wajar atau bebas dari salah saji material dan sesuai dengan Standar Akuntansi Keuangan (SAK) yang berlaku sehingga dapat dipercaya sebagai dasar pengambilan keputusan. Untuk itu, dalam memberikan opini yang tepat atau ketepatan pemberian opini, maka auditor harus memenuhi kriteria-kriteria dalam Standar Profesional Akuntan Publik (SPAP) yang berlaku. Dalam melakukan pengumpulan bukti-bukti tersebut, maka auditor harus senantiasa menggunakan
Skeptisisme Profesional Auditor agar auditor dapat menggunakan kemahiran profesionalnya dengan cermat dan seksama sehingga tujuan auditor untuk memperoleh bukti kompeten yang cukup dan memberikan basis yang memadai dalam merumuskan pendapat dapat tercapai dengan baik. (Gusti dan Ali 2008; 7).

Standar Profesional Akuntan Publik mendefinisikan Skeptisisme Profesional Auditor sebagai sikap auditor yang mencakup pikiran yang mempertanyakan dan melakukan evaluasi secara kritis selalu terhadap bukti audit (IAI, 2001). Standar auditing tersebut mensyaratkan agar auditor memiliki sikap Skeptisisme Profesional dalam mengevaluasi dan mengumpulkan 


\section{JURNAL NOMINAL / VOLUME III NOMOR 1 / TAHUN 2014}

bukti audit terutama yang terkait dengan penugasan mendeteksi kecurangan, tak terkecuali dengan auditor yang berada di Kantor Akuntan Publik (KAP) yang berada di Daerah Istimewa Yogyakarta. Sampai saat ini auditor yang tercatat di Daerah Istimewa Yogyakarta berjumlah 130 auditor yang berada pada 10 Kantor Akuntan Publik.

Erosi kepercayaan terhadap profesi akuntansi pada masa sekarang ini semakin meningkat, padahal eksistensi profesi sangat bergantung pada kepercayaan masyarakat sebagai pengguna jasa profesi. Kepercayaan masyarakat perlu dipulihkan dan hal itu sepenuhnya tergantung pada praktek profesional yang dijalankan para auditor. Munculnya kekurang percayaan masyarakat akan profesi akuntan publik memang beralasan, karena cukup banyak laporan keuangan suatu perusahaan yang mengalami kebangkrutan justru setelah mendapat opini wajar tanpa pengecualian dikeluarkan. Misalnya saja seperti kasus Enron yang melibatkan KAP Arthur Andersen di Amerika Serikat yang berakibat pada menurunnya kepercayaan investor terhadap integritas penyajian laporan keuangan. Beberapa kasus yang hampir serupa juga terjadi di Indonesia, diantaranya adalah laporan keuangan ganda Bank Lippo untuk periode 30 September pada tahun 2002 dan mark up atas laporan keuangan tahun 2001 oleh manajemen PT. Kimia Farma Tbk yang terbukti melaporkan overstated laba bersih sebesar Rp 132 miliar (Sumber: Tempo.co). Kasus pada Bank Lippo dan Kimia Farma sebenarnya kesalahan auditor adalah terlambat menyadari dan melaporkan adanya ketidakberesan yang dilakukan pihak manajemen perusahaan. Kesalahan tersebut diakibatkan karena auditor tidak menggunakan sikap Skeptisisme Profesionalnya secara memadai sehingga kurang berhati-hati dalam melakukan pengujian atas bukti audit yang seharusnya kompeten dan cukup.

Penelitian yang dilakukan oleh Beasley et al (2001) yang didasarkan pada Accounting And Auditing Realeses (AAERs) dari Securities and Exchange Commissio (SEC) menemukan bahwa urutan ketiga dari penyebab kegagalan audit adalah tingkat Skeptisisme Profesional Auditor yang kurang memadai. Dari 40 kasus audit yang diteliti SEC, 24 kasus (60\%) diantaranya terjadi karena auditor tidak menerapkan tingkat Skeptisisme Profesional Audior yang memadai (Beasley et al, 2001). Jadi rendahnya tingkat Skeptisisme Profesional Auditor dapat menyebabkan kegagalan dalam mendeteksi kecurangan. Kegagalan ini selain merugikan KAP secara ekonomis, 


\section{JURNAL NOMINAL / VOLUME III NOMOR 1 / TAHUN 2014}

juga menyebabkan hilangnya reputasi akuntan publik di mata masyarakat dan hilangnya kepercayaan kreditor dan investor di pasar modal. Dalam penelitian Gusti dan Ali (2008) Skeptisisme Profesional Auditor mempunyai hubungan dengan faktor lain seperti Pengalaman, Keahlian, Situasi Audit dan Etika yang dimiliki oleh auditor.

Pengalaman audit ditunjukkan dengan jam terbang auditor dalam melakukan prosedur audit terkait dengan pemberian opini atas laporan auditnya. Pengalaman yang dimaksudkan disini adalah Pengalaman auditor dalam melakukan pemeriksaan laporan keuangan baik dari segi lamanya waktu, maupun banyaknya penugasan yang pernah dilakukan. Semakin banyak seorang auditor melakukan pemeriksaan laporan keuangan, maka semakin tinggi tingkat Skeptisisme Profesional Auditor yang dimiliki. Seorang auditor harus terlebih dahulu mencari Pengalaman profesi di bawah pengawasan auditor senior yang lebih berpengalaman. Penelitian yang dilakukan oleh Libby dan Frederick (1990) dalam Mayangsari (2003) menemukan bahwa auditor yang berpengalaman mempunyai pemahaman yang lebih baik atas laporan keuangan. Mereka juga lebih mampu memberi penjelasan yang masuk akal atas kesalahankesalahan dalam laporan keuangan dan dapat mengelompokkan kesalahan berdasarkan pada tujuan audit dan struktur dari sistem akuntansi yang mendasari. Cara memandang dan menanggapi pada informasi yang diperoleh selama melakukan pemeriksaan antara auditor yang berpengalaman dengan yang kurang berpengalaman akan berbeda. Faktor Pengalaman merupakan salah satu elemen penting dalam tugas audit karena berpengaruh terhadap tingkat Skeptisisme Profesional Auditor. Hasil penelitian Ida Suraida (2005), memberikan bukti empiris bahwa Pengalaman berpengaruh terhadap Skeptisime Profesional Auditor walaupun pengaruhnya kecil secara parsial.

Menurut Hayes-Roth et.al (1983) dalam Mayangsari (2003) mendefinisikan Keahlian sebagai keberadaan dari pengetahuan tentang suatu lingkungan tertentu, pemahaman terhadap masalah yang timbul dalam lingkungan tersebut, dan keterampilan untuk memecahkan masalah tersebut. Dalam (IAI; 2001) auditor dapat mencapai Keahlian melalui pendidikan formal dan praktek audit, selain itu auditor harus menjalani pelatihan teknis yang cukup yang mencakup aspek teknis maupun pendidikan umum. Standar umum pertama mengatur persyaratan Keahlian auditor dalam menjalankan profesinya. Auditor harus telah menjalani pendidikan dan 


\section{JURNAL NOMINAL / VOLUME III NOMOR 1 / TAHUN 2014}

pelatihan teknis yang cukup dalam praktik akuntansi dan teknik auditing. Kasus yang terjadi pada Enron melibatkan Arthur Anderson, yaitu salah satu dari big five Certified Public Accountant (CPA) firm, yang mengaudit laporan keuangan Enron. Bagaimana mereka sampai tidak mengetahui adanya material misstatement dalam laporan keuangan Enron selama bertahun-tahun padahal Arthur Andersen adalah salah satu dari big five yang secara logika auditornya sudah memiliki Keahlian cukup memadai. Dari kasus Enron tersebut dapat diambil kesimpulan bahwa tingginya Keahlian yang dimiliki belum tentu akan menjamin auditor selalu berhasil dalam menjalankan kredibilitas sebagai auditor dengan sebagaimana mestinya.

Dalam melaksanakan tugasnya auditor seringkali dihadapkan dengan berbagai macam situasi. Menurut Shaub dan Lawrence (1996) contoh Situasi Audit seperti related party transaction, hubungan pertemanan yang dekat antara auditor dengan klien, klien yang diaudit adalah orang yang memiliki kekuasaan kuat di suatu perusahaan akan mempengaruhi Skeptisisme Profesional Auditor dalam memberikan opini yang tepat. Menurut Kee dan Knox (1970) faktor situasi berpengaruh secara positif terhadap Skeptisisme Profesional Auditor. Faktor situasi seperti
Situasi Audit yang memiliki risiko tinggi (irregularities situation) mempengaruhi auditor untuk meningkatkan sikap Skeptisisme Profesional Auditor. Menurut Arrens (2007) situasi seperti kesulitan untuk berkomunikasi antara auditor lama dengan auditor baru terkait informasi mengenai suatu perusahaan sebagai auditee akan mempengaruhi Skeptisisme Profesional Auditor.

Menurut penelitian Ida Suraida (2005) Etika auditor berpengaruh terhadap Skeptisisme Profesional Auditor. Etika profesional dibutuhkan oleh auditor untuk menjaga sikap Skeptisisme Profesional Auditor. Kesadaran etis memainkan peranan kunci dalam semua area profesi akuntan, termasuk dalam melatih sikap Skeptisisme Profesional Auditor Louwers (1997). Semakin tingginya kebutuhan masyarakat akan informasi yang andal, semakin meningkat pula kebutuhan akan akuntan publik. Namun sayang peningkatan kebutuhan tersebut tidak diikuti dengan peningkatan Etika dari profesi ini. Sesuatu yang menjadi "ujung tombak" profesi dalam membangun kepercayaan masyarakat justru menjadi sesuatu yang tidak dianggap. Contoh pelanggaran Etika pada kasus Enron adalah dilakukan oleh pihak perusahaan dan pihak auditor. Besarnya jumlah consulting fee yang diterima Arthur Andersen 


\section{JURNAL NOMINAL / VOLUME III NOMOR 1 / TAHUN 2014}

menyebabkan KAP tersebut bersedia kompromi terhadap temuan auditnya dengan pihak Enron. Keduanya telah bekerja sama dalam memanipulasi laporan keuangan sehingga merugikan berbagai pihak baik pihak eksternal seperti para pemegang saham dan pihak internal yang berasal dari dalam perusahaan enron. Kecurangan yang dilakukan oleh Arthur Andersen telah banyak melanggar prinsip Etika profesi akuntan diantaranya yaitu melanggar prinsip integritas dan perilaku profesional. KAP Arthur Andersen tidak dapat memelihara dan meningkatkan kepercayaan publik sebagai KAP yang masuk kategori The Big Five dan tidak berperilaku profesional serta konsisten dengan reputasi profesi dalam mengaudit laporan keuangan dengan melakukan penyamaran data. Kasus ini memberi gambaran bagaimana sebuah pelanggaran Etika dalam bisnis dan profesi seseorang dapat berakibat besar bagi kelangsungan hidup perusahan serta berbagai pihak yang terkait.

Dengan petimbangan tersebut maka peneliti ingin meneliti faktor-faktor apa sajakah yang dapat mempengaruhi Skeptisisme Profesinalisme Auditor dan seberapakah besar pengaruhnya pada KAP di Provinsi Daerah Istmewa Yogyakarta. Maka penelitian ini diberi judul "Pengaruh Pengalaman, Keahlian, Situasi Audit dan
Etika terhadap Skeptisisme Profesional Auditor," (Study Kasus pada KAP di Prov. Daerah Istimewa Yogyakarta).

\section{METODE PENELITIAN}

\section{Jenis Penelitian}

Jenis penelitian ini adalah penelitian kausal komparatif yang merupakan tipe penelitian ex post facto yaitu dengan mengidentifikasi fakta atau peristiwa sebagai variabel yang dipengaruhi (variabel dependen) dan melakukan penyelidikan terhadap variabel yang mempengaruhi (variabel independen). Pendekatan yang digunakan dalam penelitian ini adalah pendekatan kuantitatif.

\section{Populasi dan Sampel Penelitian}

Populasi yang akan digunakan dalam penelitian ini adalah seluruh auditor yang bekerja di Kantor Akuntan Publik (KAP) di Daerah Istimewa Yogyakarta yaitu sejumlah 10 KAP. Pengambilan sampel dilakukan dengan metode convenience sampling yaitu pemilihan sampel berdasarkan kemudahan. Penggunaan metode ini dengan alasan sulitnya peneliti bertemu dengan responden. Menurut Jogiyanto (2007:73) convenience sampling dilakukan dengan memilih sampel bebas berdasarkan faktor kemudahan yang ditentukan sendiri oleh peneliti. Jumlah sampel dalam penelitian ini ditentukan 


\section{JURNAL NOMINAL / VOLUME III NOMOR 1 / TAHUN 2014}

dengan mengacu pendapat (Suharsini Arikunto, 2006:134)

Berdasarkan pertimbangan di atas, mengingat jumlah populasi lebih dari 100 yaitu sejumlah 130 auditor, maka dalam penelitian ini akan mengambil sampel 20\%25\% dari jumlah populasi 130. Dengan pertimbangan tersebut maka penelitian ini akan mengambil 26-33 atau lebih responden sebagai sampel, berdasarkan faktor kemudahan. Dengan demikian maka penelitian ini merupakan penelitian sampel.

\section{Definisi Operasional Variabel Penelitian}

Variabel dependen pada penelitian ini yaitu Skeptisisme Profesional auditor. Skeptisisme Profesional Auditor pada penelitian ini adalah sikap yang mencakup pikiran yang selalu mempertanyakan dan melakukan evaluasi secara kritis terhadap bukti audit sebagaimana seperti definisi Skeptisisme Profesional auditor menurut Standar Profesi Akuntan Publik, (SPAP 2001: 230. 2).

Pada penelitian ini veriabel independen terdapat lima faktor yaitu Pengalaman, Keahlian, Situasi Audit, dan Etika.

Pengalaman dalam penelitian ini adalah sejauh mana jam terbang akuntan publik dalam melaksanakan tugasnya dan berapa lama waktu auditor ini memberikan jasa dalam bidang auditing.

Keahlian auditor pada penelitian ini adalah seberapa besar tingkat kemampuan, pengetahuan dan tingkat pendidikan yang dimiliki auditor.

Situasi audit adalah kondisi resiko klien yang di audit, dalam hal ini adalah kondisi laporan keuangan dan finansial dari perusahaan yang di audit.

Etika pada penelitian ini adalah suatu prinsip moral dan perbuatan yang menjadi landasan bertindaknya seseorang sehingga apa yang akan dilakukannya dipandang oleh masyarakat sebagai perbuatan yang terpuji dan meningkatkan martabat dan kehormatan seseorang

\section{Teknik Pengumpulan Data}

Teknik pengumpulan data yang digunakan dalam penelitian ini adalah menggunakan metode angket atau kuisioner. Pertanyaan berkaitan dengan data demografi responden dan tanggapan mengenai Skeptisisme Profesional Auditor, Pengalaman, Keahlian, Situasi audit dan Etika dari para auditor yang bekerja pada KAP di Daerah Istimewa Yogyakarta.

\section{Uji Asumsi Klasik}

Uji asumsi klasik yang digunakan adalah sebagai berikut.

a) Uji Normalitas 


\section{JURNAL NOMINAL / VOLUME III NOMOR 1 / TAHUN 2014}

Uji normalitas bertujuan untuk menguji apakah dalam model regresi, variabel pengganggu atau residual memiliki distribusi normal (Imam Ghozali. 2011: 160). Dalam penelitian ini normalitas dibuktikan dengan menggunakan one sample Kolmogorov-smirnov test dan $P-P$ Plot.

b) Uji Linearitas

Uji linearitas digunakan untuk mengetahui apakah variabel independen dan variabel dependen dalam penelitian ini mempunyai hubungan yang linear jika kenaikan skor variabel independen diikuti kenaikan skor variabel dependen.

c) Uji Multikolinearitas

Uji multikolinearitas diperlukan untuk mengetahui ada tidaknya variabel independen yang memiliki kemiripan dengan variabel independen lain dalam satu model.

d) Uji Heteroskedastisitas

Uji heteroskedastisitas bertujuan untuk menguji apakah dalam model regresi terjadi ketidaksamaan variance dari residual satu pengamatan kepengamatan yang lain.

\section{Uji Hipotesis}

a) Regresi Sederhana

Analisis ini digunakan menguji empat hipotesis berikut ini.
$\mathrm{H}_{1}$ : Terdapat pengaruh positif Pengalaman terhadap Skeptisisme Profesional Auditor.

$\mathrm{H}_{2}$ : Terdapat pengaruh positif Keahlian terhadap Skeptisisme Profesional Auditor.

$\mathrm{H}_{3}$ : Terdapat pengaruh positif Situasi Audit terhadap Skeptisisme Profesional Auditor.

$\mathrm{H}_{4}$ : Terdapat pengaruh positif Etika terhadap Skeptisisme Profesional Auditor.

b) Regresi Berganda

Analisis ini digunakan untuk menguji variabel bebas secara bersama-sama atau simultan terhadap variabel terikat. Dalam hal ini, analisis regresi berganda digunakan untuk menguji hipotesis kelima, yaitu.

$\mathrm{H}_{5}$ : Terdapat pengaruh positif secara simultan antara Pengalaman, Keahlian, Situasi Audit dan Etika terhadap Skeptisisme Profesional Auditor.

\section{HASIL PENELITIAN DAN PEMBAHASAN}

Uji Asumsi Klasik

Hasil uji normalitas dapat dilihat pada gambar 1. 


\section{JURNAL NOMINAL / VOLUME III NOMOR 1 / TAHUN 2014}

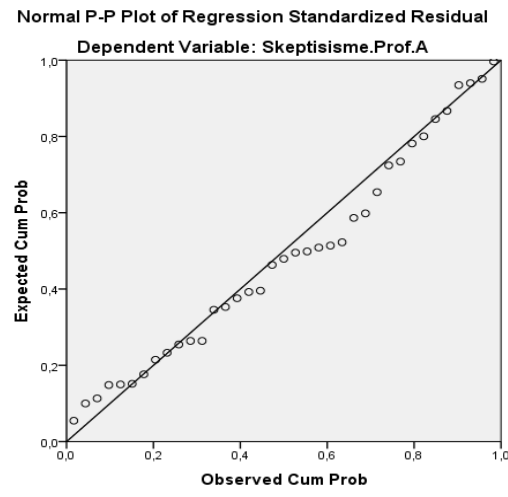

Gambar 1. Grafik P-P Plot Uji Normalitas

Dari gambar grafik di atas dapat diketahui bahwa titik-titik menyebar sekitar garis dan mengikuti garis diagonal maka dapat dikatakan nilai residual tersebut normal. Dari hasil uji normalitas menggunakan one sample KolmogorovSmirnov test, mendapatkan nilai signifikansi 0.779 dengan demikian uji normalitas melalui one sample Kolmogorov-Smirnov test dapat disimpulkan bahwa variabel penelitian terdistribusi normal karena nilai segifikansi lebih dari 0,05 yaitu 0,779.

Tabel 1 dibawah ini memperlihatkan hasil uji linearitas.

Tabel 1. Rangkuman Hasil Uji Linieritas

\begin{tabular}{cccl}
\hline No. & Korelasi & Sig & Kriteria \\
\hline 1. & $\mathrm{X}_{1}-\mathrm{Y}$ & 0,892 & Linear \\
2. & $\mathrm{X}_{2}-\mathrm{Y}$ & 0,238 & Linear \\
3. & $\mathrm{X}_{3}-\mathrm{Y}$ & 0,058 & Linier \\
4. & $\mathrm{X}_{4}-\mathrm{Y}$ & 0,899 & Linier \\
\hline
\end{tabular}

Berdasarkan tabel di atas, nilai signifikansi pengaruh Pengalaman terhadap Skeptisime Profesional Auditor sebesar 0,892, Keahlian terhadap Skeptisime Profesional Auditor sebesar 0,238, Situasi Audit terhadap Skeptisime Profesional Auditor 0,058, dan Etika terhadap Skeptisime Profesional Auditor 0,899. Nilai signifikansi tersebut lebih besar dari 0,050, sehingga dapat disimpulkan bahwa pengaruh masing-masing variabel independen terhadap variabel dependen bersifat linier.

Uji berikutnya yaitu uji multikolinearitas dapat dilihat pada tabel 2 di bawah ini.

Tabel 2. Rangkuman Uji Multikolinieritas

$$
\text { Collinearity }
$$

No Var Statistics

\begin{tabular}{ccccc} 
& & Tolerance & VIF & Ket \\
\hline 1. & $\mathrm{X}_{1}$ & 0,894 & 1.118 & \\
2. & $\mathrm{X}_{2}$ & 0,718 & 1.393 & Bebas \\
3. & $\mathrm{X}_{3}$ & 0,758 & 1.320 & Multiko- \\
4. & $\mathrm{X}_{4}$ & 0,645 & 1.550 & linieritas \\
\hline
\end{tabular}

Hasil uji multikolinearitas antar variabel bebas menunjukkan bahwa nilai Variance Inflation Factor (VIF) masing-masing variabel bebas tidak lebih dari 10 Dengan demikian dapat disimpulkan antara variabel Pengalaman, Keahlian, Situasi Audit dan 


\section{JURNAL NOMINAL / VOLUME III NOMOR 1 / TAHUN 2014}

Etika tidak terjadi

masalah

multikolinearitas

Hasil uji heteroskedastisitas diperlihatkan pada tabel 3 .

Tabel.3 Rangkuman Uji Heterokedastisitas

\begin{tabular}{cccc}
\hline No. & Korelasi & $p$-value & Kriteria \\
\hline 1. & $\mathrm{X}_{1}$ & 0,079 & Bebas \\
2. & $\mathrm{X}_{2}$ & 0,223 & Heterokedastisi- \\
3. & $\mathrm{X}_{3}$ & 0,194 & tas \\
4. & $\mathrm{X}_{4}$ & 0,404 & \\
\hline
\end{tabular}

Pengujian ini dilakukan dengan menggunakan uji Glejser. Uji Glejser digunakan untuk meregres nilai absolut residual unstandardized dan nilai variabel independen atau variabel independen ditransformasi.

Berdasar dari tabel rangkuman uji Heterokedastisitas p-value dari semua variabel independen $>0,05$ maka seluruhnya dinyatakan bebas heterokedastisitas.

\section{Uji Hipotesis}

Teknik analisis yang digunakan untuk menguji hipotesis pertama, kedua, ketiga, dan keempat pada penelitian ini menggunakan teknik analisis regresi sederhana, sedangkan untuk menguji hipotesis kelima menggunakan teknik analisis regresi berganda

\section{Uji Regresi Sederhana}

Analisis regresi sederhana digunakan untuk menganalisis hipotesis pertama, kedua, ketiga, dan keempat.

Tabel 4. Rangkuman Uji Regresi Sederhana

\begin{tabular}{|c|c|c|c|c|c|c|c|}
\hline \multirow{2}{*}{ Var } & \multicolumn{2}{|c|}{ Perhitungan } & \multicolumn{2}{|c|}{ Nilai t } & \multirow{2}{*}{ Sig } & \multirow{2}{*}{$\begin{array}{c}\text { Kons } \\
\text { tanta }\end{array}$} & \multirow{2}{*}{$\begin{array}{r}\text { Koefi } \\
\text { sien }\end{array}$} \\
\hline & $r_{(x 4 y)}$ & $r_{(x 4}^{2}$ & fitung & tabel & & & \\
\hline$X_{1}-Y$ & 0.452 & 0205 & 3000 & 1,694 & 0.005 & 46.08 & 1.398 \\
\hline $\mathrm{X}_{2}-\mathrm{Y}$ & 0.612 & 0.375 & 4,583 & 1,694 & 0.000 & 40,379 & 1.320 \\
\hline$X_{3}-Y$ & 0.594 & 0.353 & 4,368 & 1,694 & 0.000 & 28,818 & 1,350 \\
\hline $\mathrm{K}_{4}-\mathrm{Y}$ & 0.706 & 0.499 & 5,905 & 1,694 & 0.000 & 33,269 & 0,596 \\
\hline
\end{tabular}

Berdasarkan tabel di atas hasil analisis regresi sederhana diperoleh nilai koefisien korelasi $r_{(x 1 y)}$ sebesar 0,452 dan nilai koefisien determinasi $r_{(x 1 y)}^{2}$ sebesar 0,205, dapat diartikan pula besarnya pengaruh Pengalaman terhadap Skeptisisme Profesional Auditor yaitu 20,5\%. $t_{\text {hitung }}$ sebesar 3000 lebih besar dari $t_{\text {tabel }}$ yaitu 1,694 dan nilai signifikansi lebih kecil dari level of significant $(0,005<0,050)$. Besarnya nilai koefisien regresi Pengalaman $\left(\mathrm{X}_{1}\right)$ adalah 1,398 dan bilangan konstantanya 46,084. Berdasarkan angka tersebut dapat disusun persamaan garis regresi satu prediktor $\mathrm{Y}=46,084+1,398 \mathrm{X}_{1}$. Artinya jika nilai Pengalaman $\left(\mathrm{X}_{1}\right)$ bernilai 2, maka nilai Skeptisime Profesional Auditor (Y) sebesar 46,084, dan jika nilai Pengalaman naik satu satuan maka nilai Skeptisisme Profesional 


\section{JURNAL NOMINAL / VOLUME III NOMOR 1 / TAHUN 2014}

Auditor naik sebesar 1,398 satuan. Maka dapat disimpulkan hipotesis tersebut diterima yaitu terdapat pengaruh positif dan signifikan antara Pengalaman terhadap Skeptisisme Profesional Auditor.

Hasil analisis regresi sederhana diperoleh nilai koefisien korelasi $r_{(x 2 y)}$ sebesar 0,612 dan nilai koefisien determinasi $r_{(\mathrm{x} 2 \mathrm{y})}^{2}$ sebesar 0,375 , dapat diartikan pula besarnya pengaruh Keahlian terhadap Skeptisisme Profesional Auditor yaitu $37,5 \%$. thitung sebesar 4583 lebih besar dari $t_{\text {tabel }}$ yaitu 1,694 dan nilai signifikansi lebih kecil dari level of significant $(0,000<0,050)$. Besarnya nilai koefisien regresi Keahlian $\left(\mathrm{X}_{2}\right)$ adalah 1,320 dan bilangan konstantanya 40,379. Berdasarkan angka tersebut dapat disusun persamaan garis regresi satu prediktor $\mathrm{Y}=40,379+$ 1,320 $\mathrm{X}_{2}$. Artinya jika nilai Keahlian $\left(\mathrm{X}_{2}\right)$ bernilai 3, maka nilai Skeptisime Profesional Auditor (Y) sebesar 46,084, dan jika nilai Keahlian naik satu satuan maka nilai Skeptisisme Profesional Auditor naik sebesar 1,320 satuan. Maka dapat disimpulkan hipotesis tersebut diterima yaitu terdapat pengaruh positif dan signifikan antara Keahlian terhadap Skeptisisme Profesional Auditor.

Hasil analisis regresi sederhana diperoleh nilai koefisien korelasi $\mathrm{r}_{(\mathrm{x} 3 \mathrm{y})}$ sebesar 0,594 dan nilai koefisien determinasi $r_{(\times 3 y)}^{2}$ sebesar 0,353, dapat diartikan pula besarnya pengaruh Keahlian terhadap Skeptisisme Profesional Auditor yaitu $35,3 \%$. $t_{\text {hitung }}$ sebesar 4,368 lebih besar dari $\mathrm{t}_{\text {tabel }}$ yaitu 1,694 dan nilai signifikansi lebih kecil dari level of significant $(0,000<0,050)$. Besarnya nilai koefisien regresi Situasi Audit $\left(\mathrm{X}_{3}\right)$ adalah 1,350 dan bilangan konstantanya 28,818. Berdasarkan angka tersebut dapat disusun persamaan garis regresi satu prediktor $\mathrm{Y}=28,818+$ $1,350 X_{3}$. Artinya jika nilai Keahlian $\left(X_{3}\right)$ bernilai 5, maka nilai Skeptisime Profesional Auditor (Y) sebesar 28,818, dan jika nilai Situasi naik satu satuan maka nilai Skeptisisme Profesional Auditor naik sebesar 1,350 satuan. Maka dapat disimpulkan hipotesis tersebut diterima yaitu terdapat pengaruh positif dan signifikan antara Situasi Audit terhadap Skeptisisme Profesional Auditor.

Hasil analisis regresi sederhana diperoleh nilai koefisien korelasi $r_{(x 4 y)}$ sebesar 0,706 dan nilai koefisien determinasi $r_{(x 4 y)}^{2}$ sebesar 0,499, dapat diartikan pula besarnya pengaruh Etika terhadap Skeptisisme Profesional Auditor yaitu $49,9 \%$. $t_{\text {hitung }}$ sebesar 5,905 lebih besar dari $\mathrm{t}_{\text {tabel }}$ yaitu 1,694 dan nilai signifikansi lebih kecil dari level of significant $(0,000<0,050)$. Besarnya nilai koefisien regresi Etika $\left(\mathrm{X}_{4}\right)$ adalah 0,596 dan bilangan 


\section{JURNAL NOMINAL / VOLUME III NOMOR 1 / TAHUN 2014}

konstantanya 33,296. Berdasarkan angka tersebut dapat disusun persamaan garis regresi satu prediktor $\mathrm{Y}=33,296+0,596 \mathrm{X}_{3}$. Artinya jika nilai Etika $\left(\mathrm{X}_{4}\right)$ bernilai 9, maka nilai Skeptisime Profesional Auditor (Y) sebesar 33,296, dan jika nilai Etika naik satu satuan maka nilai Skeptisisme Profesional Auditor naik sebesar 0,596 satuan. Maka dapat disimpulkan hipotesis tersebut diterima yaitu terdapat pengaruh positif dan

Tabel 5. Tabel Rangkuman Uji Regresi Berganda

\begin{tabular}{|c|c|c|c|c|c|c|c|}
\hline \multirow[b]{2}{*}{ Var. } & \multicolumn{2}{|c|}{ Perhitungan } & \multicolumn{2}{|c|}{ Nilai $F$} & \multicolumn{3}{|c|}{ Unst Coefficients } \\
\hline & $\mathrm{R}_{\mathrm{y}}\left(\begin{array}{c}\mathrm{x} 1 \times 2 \\
\mathrm{x} 3 \mathrm{x} 4\end{array}\right)$ & 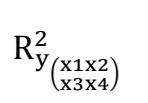 & Hit & Tab & Sig & B & Eror \\
\hline (Const, & \multirow{5}{*}{0,837} & \multirow{5}{*}{0,701} & \multirow{5}{*}{18,718} & \multirow{5}{*}{2,670} & \multirow{5}{*}{0,000} & 22,230 & 4,169 \\
\hline $\mathrm{X}_{1}$ & & & & & & 0,694 & 0,316 \\
\hline$X_{2}$ & & & & & & 0,613 & 0,246 \\
\hline$X_{3}$ & & & & & & 0,594 & 0,253 \\
\hline $\mathrm{X}_{4}$ & & & & & & 0,322 & 0,102 \\
\hline
\end{tabular}

Berdasarkan perhitungan diperoleh nilai koefisien regresi Pengalaman $\left(\mathrm{X}_{1}\right)$ sebesar 0,694, Keahlian $\left(X_{2}\right)$ sebesar 0,613, Situasi Audit sebesar 0,594 $\left(\mathrm{X}_{3}\right)$, dan Etika $\left(\mathrm{X}_{4}\right)$ sebesar 0,322, sedangkan nilai konstanta sebesar 22,230. Berdasarkan nilai tersebut maka dapat disusun persamaan garis regresi berganda sebagai berikut $\mathrm{Y}=22,230+$ $0,694 X_{1}+0,613 X_{2}+0,594 X_{3}+0,322 X_{4}$. Persamaan regresi tersebut dapat diartikan jika nilai variabel $X_{1} 2, X_{2} 3, X_{3} 5$, dan $X_{4} 9$, maka nilai $Y$ sebesar 22,2307. Koefisien regresi $\mathrm{X}_{1}$ sebesar 0,694 artinya, apabila signifikan antara Etika Audit terhadap Skeptisisme Profesional Auditor.

\section{Regresi Berganda}

Analisis regresi berganda digunakan untuk menganalisis hipotesis yang kelima. maka akan menaikkan $\mathrm{Y}$ sebesar sebesar 0,694 satuan, dengan asumsi $\mathrm{X}_{2}, \mathrm{X}_{3}$, dan $\mathrm{X}_{4}$ tetap. Koefisien regresi $X_{2}$ sebesar 0,613 artinya apabila nilai variabel $\mathrm{X}_{2}$ meningkat satu satuan maka akan menaikan Y sebesar 0,613 satuan, dengan asumsi $X_{1}, X_{3}$, dan $X_{4}$ tetap. Koefisien regresi $X_{3}$ sebesar 0,594 artinya apabila nilai variabel $\mathrm{X}_{3}$ meningkat satu satuan maka akan menaikan $Y$ sebesar 0,594 satuan, dengan asumsi $\mathrm{X}_{1}, \mathrm{X}_{2}$, dan $\mathrm{X}_{4}$ tetap. Koefisien regresi $X_{4}$ sebesar 0,322 artinya apabila nilai variabel $\mathrm{X}_{4}$ meningkat 


\section{JURNAL NOMINAL / VOLUME III NOMOR 1 / TAHUN 2014}

satu satuan maka akan menaikan Y sebesar 0,322 satuan, dengan $X_{1}, X_{2}$, dan $X_{3}$ tetap.

Hasil analisis regresi ganda menunjukkan koefisisen korelasi $\mathrm{R}_{\mathrm{y}(\mathrm{x} 1 \times 2)}$ sebesar 0,837 koefisisen determinasi $\mathrm{R}_{\mathrm{y}(\mathrm{x} 1 \times 2 \times 3 \times 4)}^{2}$ sebesar 0,701 memiliki arti variabel $X_{1}, X_{2}, X_{3}$, dan $X_{4}$ mempunyai pengaruh terhadap Y sebesar 70,1\%. Setelah dilakukan uji signifikansi dengan uji $\mathrm{F}$ diperoleh nilai $F_{\text {hitung }}$ sebesar 18,718 lebih besar dari $F_{\text {tabel }}$ yaitu 2,670. Selain itu signifikansi lebih kecil dari pada level of significant $(0,000<0,050)$. Sehingga dapat disimpulkan bahwa hipotesis kelima diterima yaitu terdapat pengaruh positif signifikan antara Pengalaman, Keahlian, Situasi Audit dan Etika secara simultan terhadap Skeptisisme Profesional Auditor.

Berdasarkan hasil analisis regresi berganda dapat diketahui besarnya sumbangan relatif dan sumbangan efektif masing-masing variabel bebas terhadap variabel terikat. Besarnya sumbangan relatif dan efektif dapat dilihat pada tabel di bawah ini.

Tabel 6. Rangkuman Sumbangan Relatif dan Efektif

\begin{tabular}{lllr}
\hline No. & \multicolumn{1}{c}{ Variabel } & SR\% & SE\% \\
\hline 1. & Pengalaman $\left(\mathrm{X}_{1}\right)$ & $11,4 \%$ & $7,99 \%$ \\
2. & Keahlian $\left(\mathrm{X}_{2}\right)$ & $19,2 \%$ & $13,46 \%$ \\
3. & Situasi Audit $\left(\mathrm{X}_{3}\right)$ & $34,6 \%$ & $24,25 \%$ \\
4. & Etika $\left(\mathrm{X}_{4}\right)$ & $34,8 \%$ & $24,39 \%$ \\
\hline
\end{tabular}

Berdasarkan analisis menggunakan perhitungan sumbangan relatif dan efektif yang tercantum pada tabel di atas dapat diketahui bahwa Pengalaman memberikan sumbangan relatif sebesar $11,4 \%$, Keahlian memberikan sumbangan relatif sebesar 19,2\%, Situasi Audit memberikan sumbangan relatif sebesar 34,6\% dan Etika memberikan sumbangan relatif sebesar $34,8 \%$. Sedangkan sumbangan efektif variabel Pengalaman sebesar 7,99\%, sumbangan efektif variabel Keahlian sebesar $13,46 \%$, sumbangan efektif variabel Situasi Audit 24,25\%, sumbangan efektif variabel Etika 24,39\%. Secara bersamasama variabel Pengalaman, Keahlian, Situasi Audit, dan Etika memberikan sumbangan efektif sebesar $70,9 \%$ terhadap Skeptisisme Profesional Auditor, dan sebesar $29,1 \%$ diberikan oleh variabel lain yang tidak dibahas dalam penelitian ini.

\section{SIMPULAN DAN SARAN}

\section{Simpulan}

Berdasarkan analisis data peneliti, maka kesimpulan yang dapat diambil dalam penelitian ini adalah (1) terdapat pengaruh positif dan signifikan Pengalaman $\left(\mathrm{X}_{1}\right)$ terhadap Skeptisisme Profesional Auditor (Y) pada KAP di Daerah Istimewa Yogyakarta. Hal ini dapat dibuktikan 


\section{JURNAL NOMINAL / VOLUME III NOMOR 1 / TAHUN 2014}

melalui analisis regresi sederhana diperoleh nilai koefisien korelasi $r_{(x 1 y)}$ sebesar 0,452 dan nilai koefisien determinasi $\mathrm{r}_{(\mathrm{x} 1 \mathrm{y})}^{2}$ sebesar 0,205, dapat diartikan pula besarnya pengaruh Pengalaman terhadap Skeptisisme Profesional Auditor yaitu 20,5\%. $\mathrm{t}_{\text {hitung }}$ sebesar 3000 lebih besar dari $t_{\text {tabel }}$ yaitu 1,694 dan nilai signifikansi lebih kecil dari level of significant $(0,005<0,050)$. Persamaan garis regresinya adalah $\mathrm{Y}=$ $46,084+1,389 \mathrm{X}_{1}$. Dapat disimpulkan bahwa jika auditor memiliki Pengalaman yang tinggi maka Skeptisisme Profesional Auditor yang dimiliki juga akan tinggi, (2) terdapat pengaruh positif dan signifikan Keahlian $\left(\mathrm{X}_{2}\right)$ terhadap Skeptisisme Profesional Auditor (Y) pada KAP di Daerah Istimewa Yogyakarta. Hal ini dapat dibuktikan melalui analisis regresi sederhana dengan nilai koefisien korelasi $\mathrm{r}_{\mathrm{x} 2 \mathrm{y})}$ sebesar 0,612 dan nilai koefisien determinasi $r_{(\mathrm{x} 2 \mathrm{y})}$ sebesar 0,375 , dapat diartikan pula besarnya pengaruh Keahlian terhadap Skeptisisme Profesional Auditor

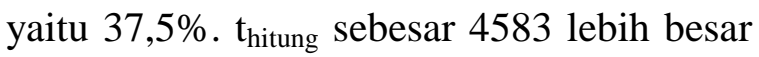
dari $t_{\text {tabel }}$ yaitu 1,694 dan nilai signifikansi lebih kecil dari level of significant $(0,000<0,050)$. Persamaan garis regresinya adalah $\mathrm{Y}=40,379+1320 \mathrm{X}_{2}$. Dapat disimpulkan bahwa jika auditor memiliki Keahlian yang tinggi maka Skeptisisme Profesional Auditor yang dimiliki juga akan tinggi, (3) terdapat pengaruh positif dan signifikan Situasi Audit $\left(\mathrm{X}_{3}\right)$ terhadap Skeptisisme Profesional Auditor (Y) pada KAP di Daerah Istimewa Yogyakarta. Hal ini dapat dibuktikan melalui analisis regresi sederhana dengan nilai koefisien korelasi $r_{(x 3 y)}$ sebesar 0,594 dan nilai koefisien determinasi $r_{(\times 3 y)}^{2}$ sebesar 0,353, dapat diartikan pula besarnya pengaruh Keahlian terhadap Skeptisisme Profesional Auditor yaitu $35,3 \%$. thitung sebesar 4,368 lebih besar dari $\mathrm{t}_{\text {tabel }}$ yaitu 1,694 dan nilai signifikansi lebih kecil dari level of significant $(0,000<0,050)$. Persamaan garis regresinya adalah $\mathrm{Y}=28,818+1,350 \mathrm{X}_{3}$. Dapat disimpulkan bahwa jika auditor menghadapi Situasi Audit dengan resiko yang tinggi maka Skeptisisme Profesional Auditor yang dimiliki juga akan tinggi, (4) terdapat pengaruh positif dan signifikan Etika $\left(\mathrm{X}_{4}\right)$ terhadap Skeptisisme Profesional Auditor (Y) pada KAP di Daerah Istimewa Yogyakarta. Hal ini dapat dibuktikan melalui analisis regresi sederhana dengan nilai koefisien korelasi $r_{(x 4 y)}$ sebesar 0,706 dan nilai koefisien determinasi $r^{2}{ }_{(x 4 y)}$ sebesar 0,499, dapat diartikan pula besarnya pengaruh Etika terhadap Skeptisisme Profesional Auditor yaitu 49,9\%. $t_{\text {hitung }}$ sebesar 5,905 lebih besar dari $t_{\text {tabel }}$ yaitu 1,694 dan nilai signifikansi lebih kecil dari level of significant $(0,000<0,050)$. 


\section{JURNAL NOMINAL / VOLUME III NOMOR 1 / TAHUN 2014}

Persamaan garis regresinya adalah $\mathrm{Y}=$ $33,296+0,596 X_{4}$. Dapat disimpulkan bahwa jika auditor memiliki Etika yang tinggi maka Skeptisisme Profesional Auditor yang dimiliki juga akan tinggi, (5) terdapat pengaruh positif dan signifikan secara bersama antara Pengalaman $\left(\mathrm{X}_{1}\right)$, Keahlian $\left(\mathrm{X}_{2}\right)$, Situasi Audit $\left(\mathrm{X}_{3}\right)$ dan Etika $\left(\mathrm{X}_{4}\right)$ terhadap Skeptisisme Profesional Auditor (Y) pada KAP di Daerah Istimewa Yogyakarta. Hal ini dapat dibuktikan melalui hasil analisis regresi ganda menunjukkan koefisisen korelasi $\mathrm{R}_{\mathrm{y}(\mathrm{x} 1 \mathrm{x} 2)}$ sebesar 0,837 korelasi determinasi $\mathrm{R}_{\mathrm{y}(\mathrm{x} 1 \times 2 \times 3 \times 4)}^{2}$ sebesar 0,701 memiliki arti variabel $\mathrm{X}_{1}, \mathrm{X}_{2}, \mathrm{X}_{3}$, dan $\mathrm{X}_{4}$ mempunyai pengaruh terhadap Y sebesar $70,1 \%$. Setelah dilakukan uji signifikansi dengan uji $F$ diperoleh nilai $F_{\text {hitung }}$ sebesar 18,718 lebih besar dari $F_{\text {tabel }}$ yaitu 2,670. Selain itu signifikansi lebih kecil dari pada level of significant $(0,000<0,050)$. Persamaan garis regresinya adalah $\mathrm{Y}=22,230+0,694 \mathrm{X}_{1}+$ $0,613 X_{2}+0,594 X_{3}+0,322 X_{4}$. Dapat disimpulkan bahwa jika auditor memiliki Pengalaman, Keahlian yang tinggi, Situasi Audit yang dihadapi dengan resiko yang tinggi dan memiliki Etika yang tinggi, maka Skeptisisme Profesional Auditor yang dimiliki juga akan tinggi.

\section{Saran}

Beberapa saran yang dapat diberikan dari penelitian ini adalah sebagai berikut:

1) Melihat hasil karakteristik responden dimana mendalami pengetahuan kode etik yang mendapatkan hasil bahwa secara umum responden masih jarang yang mendalami kode etik diluar bangku kuliah seperi kursus kode etik dan kursus akuntansi dan modul kode etik, peneliti memberi saran supaya KAP di Daerah Istimewa Yogyakarta mengikutsertakan staff dan para auditor yunior untuk mengikuti pelatihan atau kursus mengenai kode etik guna pendalaman kode etik tersebut. Kesadaran etis serta kepedulian pada Etika profesi yang merupakan faktor pembentuk ketaatan pada etika hendaknya terus dipelihara dan ditingkatkan. Auditor dapat mengikuti berbagai penyuluhan tentang Etika dan moral melalui siraman rohani guna meningkatkan kesadaran etis auditor. Kesadaran etis auditor perlu dijaga oleh setiap auditor KAP sebagai bekal dalam mempertahankan kredibilitas profesi. Selain hal tersebut mengingat penelitian ini mendapatkan hasil bahwa Etika berpengaruh secara positif dan segnifikan terhadap Skeptisisme Profesional Auditor dan pengaruhnya 


\section{JURNAL NOMINAL / VOLUME III NOMOR 1 / TAHUN 2014}

paling dominan diantara faktor yang lain yaitu sebesar $49,9 \%$.

2) Melihat hasil dari tabel distribusi frekuensi terkait variabel Pengalaman yang menunjukan bahwa auditor secara umum cenderung memiliki Pengalaman yang masih tergolong sedang dan rendah. Peneliti menyarankan agar auditor KAP di Daerah Istimewa Yogyakarta lebih meningkatkan lagi faktor Pengalaman. Untuk meningkatkan Pengalaman, auditor dapat mengikuti penugasan audit yang lebih banyak lagi. Pengetahuan, Keahlian, keterampilan dan Pengalaman auditor dan staff supaya juga perlu untuk terus ditingkatkan melalui pelatihan dan mengikutsertakan auditor beserta staf pada berbagai seminar yang berkaitan dengan profesi akuntan publik baik didalam negeri maupun luar negeri. Hal tersebut disarankan peneliti mengingat hasil penelitian ini mendapatkan hasil bahwa Pengalaman berpengaruh positif dan segnifikan dengan Skeptisisme Profesional Auditor.

3) Penelitian ini menghasilkan kesimpulan terdapat pengaruh positif dan signifikan antara Situasi Audit dengan Skeptisisme Profesional Auditor. Maka dapat diartikan bahwa semakin tinggi
Situasi Audit akan resiko maka Skeptisisime Profesional Auditor juga akan tinggi. Demikian juga sebaliknya jika semakin rendah Situasi Audit yang dihadapi akan resiko maka semakin rendah Skeptisisme Profesional Auditor. Peneliti memberikan saran sebaiknya auditor KAP di Daerah Istimewa Yogyakarta tetap menggunakan sikap Skeptisisme Profesional Auditornya secara tinggi pada Situasi Audit apapun mengingat bahwa standar auditing yang mensyaratkan agar auditor memiliki sikap Skeptisisme Profesional dengan baik dalam mengevaluasi dan mengumpulkan bukti audit terutama yang terkait dengan penugasan mendeteksi kecurangan. Dengan demikian dapat diartikan juga bahwa auditor juga harus menggunakan Skeptisisme Profesionalnya dengan baik dan sebaiknya tidak terpengaruh dengan Situasi Audit yang dihadapi.

4) Berdasarkan perhitungan menggunakan koefisien determinasi, secara bersamasama pengaruh Pengalaman, Keahlian, Situasi Audit dan Etika terhadap Skeptisisme Profesional Auditor sebesar $70,1 \%$ dan sisanya dipengaruhi oleh faktor lain. Dengan demikian dapat disimpulkan pengaruh tersebut sangat 


\section{JURNAL NOMINAL / VOLUME III NOMOR 1 / TAHUN 2014}

dominan, sehingga setiap auditor pada

KAP di Daerah Istimewa Yogyakarta diharapkan harus senantiasa meningkatkan Pengalaman, Keahlian, Etika, serta, memperhitungkan risiko audit dengan tepat pada setiap Situasi Audit, guna meningkatkan Skeptisisme Profesional.

5) Berdasarkan perhitungan menggunakan koefisien determinasi, secara bersamasama pengaruh Pengalaman, Keahlian, Situasi Audit dan Etika terhadap Skeptisisme Profesional Auditor sebesar $70,1 \%$ dan sisanya dipengaruhi oleh faktor lain. Dengan demikian auditor diharapkan juga memperhatikan faktor lain guna meningkatkan Skeptisisme Profesional Auditor misalnya seperti faktor ketaatan beragama dan kepastian hukum.

6) Penelitian ini menghasilkan kesimpulan terdapat pengaruh positif dan signifikan antara Etika dengan Skeptisisme Profesional Auditor. Maka dapat diartikan bahwa semakin tinggi Etika yang dimiliki auditor maka Skeptisisime Profesional Auditor juga akan tinggi. Demikian juga sebaliknya jika semakin rendah Etika yang dimiliki auditor maka semakin rendah Skeptisisme Profesional Auditor. Diantara variabel yang lain Variabel Etika memiliki pengaruh yang paling dominan yaitu sebesar 49,9\%, dengan demikian IAI diharapkan terus menggalakan penyuluhan tentang etika dan moral antara lain melalui siraman rohani yang diberikan secara berkala, seminar tentang etika bisnis, etika profesi dan lain-lain guna meningkatkan Etika auditor.

7) Untuk mengurangi kasus terkait pelanggaran Etika yang dilakukan oleh auditor, IAI diharapkan memberikan sanksi yang tegas pada auditor yang melanggar kode etik profesi guna menjaga Skeptisisme Profeional Auditor serta mengingat pada penelitian ini variabel Etika berpengaruh paling dominan diantara variabel yang lain.

8) Mengingat masih ada variabel lain di luar faktor Pengalaman, Keahlian, Situasi Audit dan Etika yang bisa mempengaruhi Skeptisisme Profesional Auditor peneliti selanjutnya diharapkan mengidentifikasi dan menambahkan faktor lain yang bisa mempengaruhi Skeptisisme Profesional Auditor misalnya seperi faktor ketaatan beragama dan kepastian hukum.

9) Penelitian selanjutnya diharapkan menggunakan pertanyaan pada angket kuesioner yang lebih simpel agar mudah dipahami dan tidak terlalu menyita waktu responden mengingat 


\section{JURNAL NOMINAL / VOLUME III NOMOR 1 / TAHUN 2014}

tingginya jam terbang responden menjadi auditor.

10) Penelitian selanjutnya diharapkan waktu penelitian dilakukan pada saat waktu dimana auditor tidak sedang melakukan banyak tugas audit agar peneliti selanjutnya lebih bisa mendapatkan lebih banyak sampel penelitian.

\section{DAFTAR PUSTAKA}

Achmat, Zakarija. (2010). Theory of Planned Behavior, Masihkan Relevan?. Diambil dari: http://zakarija.staff.umm.ac.id/files/20 10/12/, diakses tanggal 26 Februari 2013

Agoes. (2004). Auditing (Pemeriksaan Akuntan) oleh Akuntan Publik. Jakarta: Lembaga Penerbit Universitas Indonesia.

Agung, Mangaraja. (2007). "Disonansi Kognitif.” Literatur. Fakultas Psikologi, Universitas Indonesia

Ajzen, Icek. (1991). Organizational Behavior and Human Decison Process: Theory of Planned Behavior Online's. http://home.comcast.net/ajzen/tpb.obhdp-295, diakses tanggal 20Februari 2013.

Ameliyah, Siska. (2012). Pengaruh Kompetensi dan Independensi
Terhadap Kualitas Audit Dengan Ukuran KAP Sebagai Variabel Moderator. Universitas Trisakti.

Ansah, S. O., Moyes, G. D., Oyelere, P. B., Hay, D. (2002). “An Empirical Analysis of the Likelihood of Detecting Fraud in New Zealand." Managerial Auditing Journal. Vol. 17. No. 4.

Arrens. (2007). Auditing dan Pelayanan Verifikasi : Pendekatan Terpadu. Jakarta: Tim Dejacarta.

Asih. (2006). Pengaruh Pengalaman Terhadap Peningkatan Keahlian Auditor dalam Bidang Auditing. Skripsi. Tidak Dipublikasikan.

Azwar, S. (1998). Sikap Manusia Teori dan Pengukurannya. Jakarta : Pustaka Pelajar.

Bawono, I. R., Singgih, E. M. (2009). "Faktor-faktor dalam Diri Auditor dan Kualitas Audit : Studi Pada KAP "Big Four" di Indonesia. Jurnal Simposium Nasional Akuntansi13 Purwokerto.

Beasley, M.S., Carcello, J.V., and Hermansen, D, R. "Top 10 Audit Defienciencies. "Journal of Accountancy (April 2001): 63-66.

Bhuono Agung Nugroho. (2005). Strategi Jitu Memilih Metode Statistik 


\section{JURNAL NOMINAL / VOLUME III NOMOR 1 / TAHUN 2014}

Penelitian Dengan SPSS. Yogyakarta: CV Andi Offset.

Butt, J. I. (1998). “Frequency Judgments I an Auditing - Related Lask." Journal of Accounting Research. Vol.26.

Gusti, Magfirah., Syahrir, Ali. (2008). "Hubungan Skeptisisme Profesional Auditor dan Situasi Audit, Etika, Pengalaman serta Keahlian Audit dengan Ketepatan Pemberian Opini Auditor oleh Akuntan Publik". Jurnal Simposium Nasional Akuntansi Padang. Vol.8.

Herdiansyah, Yudhi. (2008). Metodologi Penelitian: Pusat Pengembangan Bahan Ajar. Jakarta: Universitas Mercubuana

Herusetya, Antonius.(2007). “Kewajiban Hukum Bagi Akuntan Publik: Resiko Profesional yang Semakin Meningkat". Jurnal Akuntansi dan Keuangan. Vol.1, No.1.

Ida, Suraida. (2005). "Pengaruh Etika, Kompetensi, Pengalaman Audit dan Risiko Audit terhadap Skeptisisme Profesional Auditor dan Ketepatan Pemberian Opini Akuntan Publik". Sosiohumaniora, Vol. 7 No. 3, November 2005: 186-202

Ikatan Akuntan Indonesia. (2001). Standar Profesional Akuntan Publik. Jakarta: Salemba Empat.
Imam, Ghazali. (2009). Aplikasi Analisis Multivariat dengan Program SPSS. Semarang: UNDIP. . (2011). Aplikasi Analisis Multivariat Dengan Program IBM SPSS 19. Semarang: UNDIP.

Indiantoro \& Bambang Supomo. (2002) Metodologi Penelitian Bisnis Cetakan Kedua. BPFE. Yogyakarta.

Kee, H. W., Knox, R. E. (1970). "Conceptual and Methodological Consideration in the Study of Trust and Suspicion." The Journal of Conflict Resolution. Vol.14, No.3.

Jeffrey, Cynthia. (1996). "Ethical Development, Professional Commitment, and Rule Observance Attitudes: A Study of CPAs and Corporate Accountants." Behavioral Research in Accounting. Vol.8 Jogiyanto. (2007). Metodologi Penelitian Bisnis: Salah Kaprah dan Pengalaman pengalaman. Cetakan pertama. Yogyakarta: BPFE.

Kriswandari, Tutik. (2006). "Pengaruh Pengalaman, Situasional dan Disposisional terhadap Kepercayaan atau Kecurigaan Auditor terhadap Klien." Tesis Tidak Dipublikasikan. Program Pascasarjana, Universitas Diponegoro. 


\section{JURNAL NOMINAL / VOLUME III NOMOR 1 / TAHUN 2014}

Kusharyanti. (2003). “Temuan Penelitian Mengenai Kualitas Audit dan Kemungkinan Topik Penelitian di Masa Datang". Jurnal Akuntansi dan Manajemen: Desember.

Louwers, T. J., Ramsay, R. J., Sinason, D. H. (2005). Auditing and Assurance Service. New York: Mc Graw Hill.

Mayangsari, Sekar. (2008). Pengaruh Keahlian Audit dan Indepedensi terhadap Pendapat Audit : Sebuah Kuasieksperimen. Jurnal Riset Akuntansi Indonesia Vo. 6. No. 1: 1 22.

Mulyadi. (2002). Auditing, Buku dua Edisi ke Enam. Jakarta: Salemba Empat.

Noviyanti, Suzy. (2008). "Skeptisisme

Profesional Auditor dalam Mendeteksi Kecurangan untuk Mencapai Prosedur Audit yang Efektif." Disertasi. Program Doktor, Universitas Diponegoro.

Pangeran. (2011). Etika Profesi Akuntansi,

Diambil dari:

http://community.gunadarma.ac.id/blo g/viewid-77215/title-etika-profesiakuntansi/, diakses tanggal 5 Maret 2013.

Ricky Griffin dan Ronald J. Ebert. (2006).

Bisnis Edisi Kedelapan. Jakarta: Erlangga.
Shaub, M.K., Lawrence, J. E. (1996). "Ethics, Experience and Profesional Scepticism: A Situational Analysis." Behavioral Research in Accounting. Vol.8.

Sofyan, Yami, dkk. (2011). Regresi dan Korelasi dalam Genggaman Anda. Jakarta: Salemba Empat.

Sonny, Keraf. (1998), Etika Bisnis Tuntutan dan Relevansinya, Jogjakarta: Kanisius.

Sugiyono.(2008). Metode Penelitian Bisnis. Bandung: CVAlfabeta. .(2012). Statistik Untuk

Penelitian. Bandung: CVAlfabeta.

Suharsimi, Arikunto. (2006). Prosedur Penelitian Suatu Pendekatan praktik. Jakarta:PT Rineka Cipta

Suprianto, Edy., Hendry, Setiawan. (2010). "Pengaruh Etika, Kompetensi, Pengalaman audit Dan Resiko Audit Terhadap Skeptisisme Profesional Auditor Dan Ketepatan Pemberian Opini Auditor". Laporan Penelitian Dosen Muda. Universitas Islam Sultan Agung.

Sutrisno Hadi. (2004). Analisis Regresi. Yogyakarta: CV Andi Offset.

Tempointeraktif.com. (2002). Pemerintah Akan Berikan Sanksi kepada Akuntan Publik Kimia Farma. Diambil dari: 
http://www.tempo.co/read/news,

diakses tanggal 12 Februari 2013

Tempointeraktif.com. (2003). Bapepam

Akan Tuntaskan Kasus Lippo dalam

Bulan Ini. Diambil dari:

http://www.tempo.co/read/news,

diakses tanggal 12 Februari 2013

Tuanakotta, T. M. (2011). Berpikir Kritis

dalam Auditing. Jakarta: Salemba

Empat.

Zulaikha. (2006). "Pengaruh Interaksi

Gender, Kompleksitas Tugas dan Pengalaman Auditor terhadap Audit Judgment." Jurnal Simposium Nasional Akuntansi 9 Padang. 